\title{
How the effects of aging and stresses of life are integrated in mortality rates: insights for genetic studies of human health and longevity
}

\author{
Anatoliy I. Yashin $\cdot$ Konstantin G. Arbeev $\cdot$ Liubov S. Arbeeva \\ Deqing Wu • Igor Akushevich • Mikhail Kovtun • Arseniy Yashkin • \\ Alexander Kulminski - Irina Culminskaya - Eric Stallard • \\ Miaozhu Li $\cdot$ Svetlana V. Ukraintseva
}

Received: 13 April 2015/ Accepted: 25 July 2015/Published online: 18 August 2015

(C) Springer Science+Business Media Dordrecht 2015

\begin{abstract}
Increasing proportions of elderly individuals in developed countries combined with substantial increases in related medical expenditures make the improvement of the health of the elderly a high priority today. If the process of aging by individuals is a major cause of age related health declines then postponing aging could be an efficient strategy for improving the health of the elderly. Implementing this strategy requires a better understanding of genetic and non-genetic connections among aging, health, and longevity. We review progress and problems in research areas whose development may contribute to analyses of such connections. These include genetic studies of human aging and longevity, the heterogeneity of populations with respect to their susceptibility to
\end{abstract}

A. I. Yashin - K. G. Arbeev - L. S. Arbeeva .

D. Wu · I. Akushevich · M. Kovtun · A. Yashkin ·

A. Kulminski · I. Culminskaya - E. Stallard ·

M. Li · S. V. Ukraintseva

The Biodemography of Aging Research Unit, Social

Science Research Institute, Duke University, Durham, $\mathrm{NC}$, USA

\section{A. I. Yashin $(\square)$}

The Biodemography of Aging Research Unit, Social Science Research Institute, Duke University, 2024 W. Main Street, Room A102E, Durham, NC 27705, USA e-mail: aiy@duke.edu

\section{S. V. Ukraintseva ( $\square)$}

The Biodemography of Aging Research Unit, Social Science Research Institute, Duke University, 2024 W. Main Street, Room A105, Durham, NC 27705, USA disease and death, forces that shape age patterns of human mortality, secular trends in mortality decline, and integrative mortality modeling using longitudinal data. The dynamic involvement of genetic factors in (i) morbidity/mortality risks, (ii) responses to stresses of life, (iii) multi-morbidities of many elderly individuals, (iv) trade-offs for diseases, (v) genetic heterogeneity, and (vi) other relevant aging-related health declines, underscores the need for a comprehensive, integrated approach to analyze the genetic connections for all of the above aspects of aging-related changes. The dynamic relationships among aging, health, and longevity traits would be better understood if one linked several research fields within one conceptual framework that allowed for efficient analyses of available longitudinal data using the wealth of available knowledge about aging, health, and longevity already accumulated in the research field.

Keywords Longitudinal data $\cdot$ Genetic heterogeneity · Pleiotropy · Population aging · Quadratic hazard · Health of the elderly

\section{Introduction}

Demographic trends in developed countries and other parts of the world are characterized by reductions in fertility and mortality rates that result in an increase in the proportion of elderly individuals in the 
corresponding populations. Elderly people have higher risks of developing chronic diseases than younger people, their health conditions are characterized by multi-morbidity, so the treatment of their disorders is more difficult and involves higher medical costs. The health expenditures in these countries may increase substantially in the near future. In the U.S., Medicare spending alone is projected to roughly double as a share of gross domestic product, from $3.7 \%$ in 2012 to $7.3 \%$ in 2050 (Goldman et al. 2013). This situation raises concerns about whether and how the health of the elderly could be improved.

One idea for improvement recognizes that each person's age is a strong predictor of the risks of onset for many chronic diseases, suggesting a causal connection between aging and health. Studies of aging in animal model systems provide evidence supporting this view. The development of multi-morbidity among the elderly may be linked to the aging process: genes associated with multi-morbidity (e.g., having pleiotropic associations with several aging-related disorders) may be involved in the regulation of aging. If so, then slowing down or postponing aging may reduce the incidence of age related diseases (Barzilai and Rennert 2012; Hamerman 2010; Miller 2009; Olshansky et al. 2007; Warner et al. 2005). Implementing this idea requires a deeper understanding of how the biological mechanisms that link individual aging with morbidity and mortality risks respond to external and internal challenges (e.g., changes in the environment, medical interventions, ontogenetic changes, etc.). We know that the biological responses are formed using genetic signaling, metabolic, and other pathways and networks. Such links make genetic studies of these processes important components of research focused on the connections among aging, health, and mortality/longevity. These studies will likely have important practical implications: they will help find efficient ways of improving the health of the elderly in an aging world.

The connections between aging and diseases of the elderly are complicated. For many chronic diseases the incidence rates do not increase monotonically with age: instead, they first increase, reach their maximum values, and then decline. Some people with exceptional longevity never develop major chronic conditions (Evert et al. 2003). Some disease pairs have the form of a trade-off: an increase in incidence of one disease might be accompanied by a decline in incidence of another disease. Some genetic and non- genetic risk factors may change their associations with morbidity and mortality risks during the life course as a result of aging-related changes. They may exhibit different effects on morbidity and mortality in independent populations because of exposures to different environments, medical interventions, etc. (Akushevich et al. 2013; Kulminski et al. 2011; Thinnes 2012; Tremolizzo et al. 2006; Ukraintseva et al. 2010; Yashin et al. 2009).

Some problems that might shed light on relationships among aging, health, and longevity were investigated without paying attention to systemic dynamic aspects of their possible mutual connections. These include studying roles of genetic factors in human aging and longevity, identifying forces and mechanisms shaping age patterns and time trends of human mortality and survival curves, investigating health and survival outcomes resulting from interactions between aging-related changes and responses to environmental stresses, and studying how external challenges and genetic factors (dynamically integrated by physiological variables and other biomarkers) interact with aging-related changes (represented by the decline in resistance to stresses and resilience) during the life course of genetically different individuals to affect health and survival. Taken together these studies could create a solid basis for comprehensive and efficient, high-priority analyses of systemic aspects of dynamic relationships among aging, health, and longevity. In this paper, we review these research directions paying attention to their mutual connections.

\section{Progress and problems in genetic studies of human aging and longevity}

Recent genetic studies of aging and longevity in animal model systems indicate that substantial progress has been made in understanding the roles of genes, signaling and metabolic pathways, and genetic networks in aging and longevity. Many such pathways are evolutionarily conserved in different species, including humans, suggesting that efficient translation of the research findings from these studies to human clinical practice may be possible. To date, however, such translation has been slower than expected. Attempts to confirm findings from animal studies using data on human aging and longevity have had limited success (de Magalhaes 2014; Morris et al. 2014). Despite 
substantial progress in clarifying certain aspects of genetic regulation of aging and longevity traits in humans, many research findings in genome-wide association studies (GWAS) of these traits have not reached genome-wide levels of statistical significance. They also suffered from the lack of replication using data from independent populations (Lunetta et al. 2007; Newman et al. 2010; Walter et al. 2011). Studies of genetic associations with chronic diseases and other phenotypes related to health disorders appeared to be more efficient. Nonetheless, the interpretations of these research findings in terms of mechanisms connecting aging, health, and longevity remain elusive. Small sample sizes are often blamed for the weakness of genetic signals and the lack of genome wide significance. However, recent genetic analyses of human longevity using larger sample sizes have not improved the situation (Broer et al. 2015; Deelen et al. 2014). In Broer end colleagues, the authors used a sample of 6036 longevity cases (persons who survived to age 90 years) and 3757 controls. Their analyses confirmed the association of FOXO3 and $A P O E$ with longevity, but did not find any new associations aside from the suggestive evidence for CADM2 and GRIK2. In Deelen and colleagues the authors used a sample of over 20,000 long-lived individuals. Apart from the wellknown association on the TOMM40/APOE/APOC1 locus, the authors found only one new association, on chromosome 5q33.3. These results indicate that increasing sample size does not always resolve the problems of "weak signals" and lack of replication. One reason could be the large inherent heterogeneity of aging and longevity traits. Indeed, an increase in a sample size may result in an unanticipated increase of genetic heterogeneity of a trait in a sample (Baird and Caldas 2013; Eichler et al. 2010; MacRae and Vasan 2011). This possibility underscores the need to take into account hidden genetic and non-genetic heterogeneity in susceptibility to disease and death in humans. The next section discusses intensive studies of hidden heterogeneity performed in connection with their roles in shaping the age patterns of mortality rates.

\section{Which forces shape the age patterns of human mortality rates?}

Age patterns of mortality rates in population cohorts represent the integration of the influences of thousands of factors of genetic and non-genetic origins affecting individuals' mortality risks at different periods of their lives. Remarkably, despite the large number and high variability of influential factors the age patterns of mortality rates in laboratory animals and humans at the "intervals of aging" (between ages 35 and 85 years in humans) follow the Gompertz or Gompertz Makeham laws (Kirkwood 2015). At late ages the shapes of the mortality rates may deviate downward from the Gompertz curve (Carey et al. 1992; Vaupel et al. 1998). To explain such deviations the concept of hidden heterogeneity in individual mortality risks was introduced. This concept recognizes that population members may differ in their health and survival responses to the same stresses of life, and these differences together with their distribution in the population influence the shapes (age patterns) of observed (total) mortality rates. The heterogeneity variable may have biological, environmental, or other interpretations depending on the context, including study design and conditions (Abbring and Van den Berg 2007; Carnes and Olshansky 2001; Vaupel and Yashin 1985; Zajacova et al. 2009). Vaupel and colleagues introduced important class of survival models with hidden heterogeneity, called "frailty models" (Vaupel et al. 1979).

\section{Hidden frailty}

In survival analysis, "frailty" is a measure of mortality risk in the proportional hazards model. Frailty is a nonnegatively distributed random variable that summarizes the unobserved effects of individual genetic and non-genetic factors on mortality risk. This variable has an unknown probability distribution. This distribution and an associated baseline hazard function can be estimated from mortality data using additional assumptions. Frailty models were introduced to explain the deceleration and leveling off of the age trajectories of mortality rates at late ages. Vaupel and colleagues summarized the evidence for such behaviors for mortality curves calculated from data on large populations of laboratory animals (Vaupel et al. 1998). Frailty models were successfully implemented in analyses of various survival problems (Aalen 1994; Aalen et al. 2014; Hougaard et al. 1994; Lee et al. 2014a; Semenchenko et al. 2004). Although the fixed frailty models allowed better descriptions of late age mortality curves, they provided little information 
about the dynamic biological mechanisms influencing these curves. To facilitate the study of such mechanisms, models of changing heterogeneity (frailty) were developed and compared with the fixed frailty models. It was discovered that that the class of models with randomly changing heterogeneity variables is parametrically indistinguishable from the class of fixed frailty models (Yashin et al. 1994). This finding indicated that additional information is needed to better understand the forces and dynamic mechanisms involved in regulating the age trajectories of mortality rates. Some information can be added by introducing explanatory variables (observed covariates) into the fixed frailty models. The presence of hidden frailty downwardly biases the estimates of the effects of observed covariates on mortality risks; hence, hidden frailty cannot be safely ignored (Hougaard 1995, 1999).

Underutilized research potential of available data and methods

Models of genetically heterogeneous populations are useful in genetic analyses of data on human longevity. They provide efficient methods for the joint analyses of lifespan data on genotyped and non-genotyped individuals (Yashin et al. 2007, 1999, 2000). These methods can be further extended to deal with longitudinal data for genotyped and non-genotyped individuals (Arbeev et al. 2011). Their use underscores the importance, for genetic analyses of follow-up data, of population age structure at the time of biospecimen (e.g., blood) collection (Yashin et al. 2013b). The biodemographic view of exceptional longevity facilitates the development of efficient methods for correcting for population stratification in genetic studies of human longevity (Yashin et al. 2014). These methods recognize that genetic structure in a study population generated by differences in ancestry can be modified by mortality selection. The most efficient approach is to separate the two sources of population stratification and use only the first as a control for stratification in genetic analyses of lifespan data. Thus, the use of biodemographic ideas, models, and methods in studying genetic and non-genetic effects on aging, health, and longevity may substantially improve the quality of analyses. The next section discusses biodemographic aspects of the connections between genetic factors and longevity related traits and their importance in understanding trends in survival improvement in developed countries and other parts of the world during the past two to three centuries (Beltran-Sanchez et al. 2012; Yashin et al. 2001a).

\section{Progress in survival improvement: Insights for genetic studies of human longevity}

The non-Gompertzian behavior of mortality curves at late ages motivated the development of the heterogeneity/frailty models. The unexpected regularities in survival improvement in populations of developed countries also required explanation. Figure 1 shows changes in survival in female populations in Italy during 1872-2009 and Sweden during 1751-2011. The changes in male survival in these countries, as well as in other developed countries during the past two to three centuries, followed similar patterns.

Survival improvement in the first half of the 20th century followed the "rectangularization" pattern (Fig. 1). This pattern was characterized by an increase in survival for which the mean lifespan was increasing,

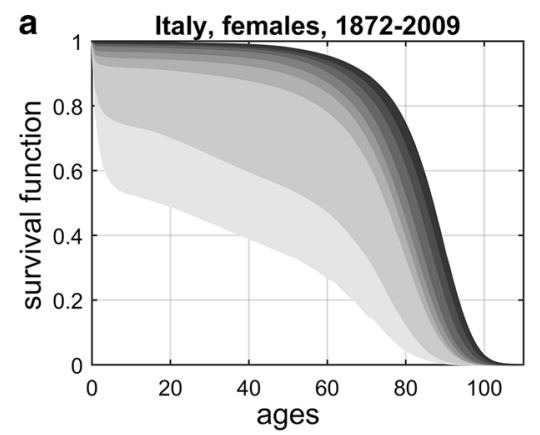

1872-1919

$1920-1949$

1950-1959

1960-1969

1970-1979

$1980-1989$

1990-1999

2000-2009

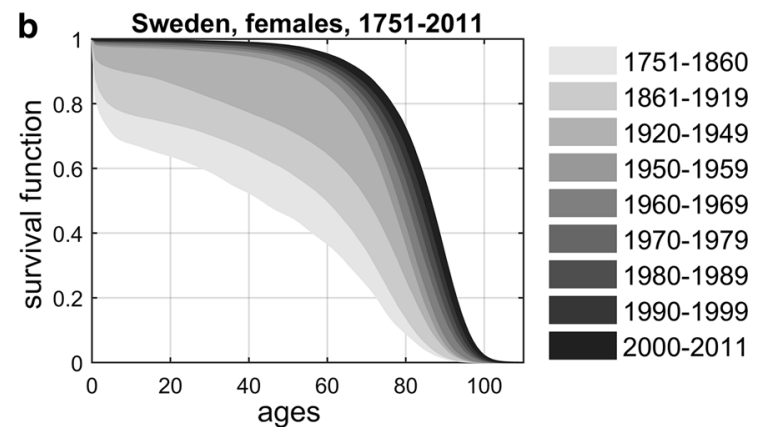

Fig. 1 The age patterns of survival improvement in Italy (a) and in Sweden (b) obtained from the Human Mortality Database (HMDB) 
the variance was declining, and the maximum lifespan remained about the same. In the second half of the 20th century the rectangularization pattern of survival improvement was replaced by an almost parallel shift of the entire survival curve to the right. The new pattern was characterized by an increase in the mean and maximum lifespans, and by almost no changes in the variance of the lifespan distributions. The reasons for such improvements were the subjects of intensive debates for several decades. Some researchers argued that social and economic developments were responsible for positive trends in health and survival (Colgrove 2002; Link and Phelan 2002; McKeown et al. 1975). The better quality of nutrition was emphasized in (Alfin-Slater 1979; Kesteloot 1993; Niculescu and Lupu 2011). Others provided evidence of important roles of health care and advances in medicine (Abelson 1993; Bunker 2001; Mackenbach 1996). Better understanding of the reasons for these trends can help us interpret the results of genetic analyses of human aging and longevity.

Reduction in stress load contributed to survival improvement

Stress response is the way that living organisms adjust their behavior and functioning to changing environments. There are evolutionarily developed connections between resistance to stresses and longevity (Calabrese et al. 2011; Epel and Lithgow 2014; Jazwinski 2005; Kirkwood et al. 2000; Le Bourg 2009; Parsons 1996, 2007; Vermeulen and Loeschcke 2007). Improvements in survival may occur because of: (i) reductions in harmful stress loads; or (ii) increases in individual stress resistance. Exposures to more favorable environmental and living conditions were likely, over time, to have reduced deleterious stress loads and improved the survival of individuals. The biological mechanisms may involve responses to smaller frequencies and magnitudes of external challenges (see "Mortality and aging: how are they related?" section below) resulting in smaller deviations of biological variables from their normal values (see "Integrative mortality models" section below).

Progress in health care and medicine may also have contributed to the continuing mortality decline. The development of health care and medicine enhanced each individual's limited capacities for coping with diseases and withstanding other deleterious consequences of human interactions with harmful and unfriendly environments. In other words, progress in health care and medicine enhanced each organism's resilience and resistance to stresses. Such contributions may have generated the rectangularization pattern of survival improvement seen in Fig. 1 (Yashin et al. 2012b). Although the development of the health care industry followed basic economic principles, this system should also function in concordance with internal biological and physiological processes regulated by genes and modulated by external conditions. The genetic factors involved in the mediation of the effects of medical interventions on health status and lifespan are likely to include those dealing with common responses to stress, as well as intervention-specific genetic factors. Hence, the genetic polymorphisms that were able to efficiently interact with medical and health care interventions affecting variability in health and longevity are likely to be detectable in genetic association studies of those traits.

Better food-longer life?

A third mode of favorable external changes relates to improved nutrition. Several recent publications provide evidence that a balanced diet rich in vitamins and other important nutrients contributes to an increase in individual resistance to stresses (Bosma-den Boer et al. 2012; Sisodia and Singh 2012) and, hence, in lifespan and survival (Cai et al. 2015; Chedraui and Perez-Lopez 2013; Crous-Bou et al. 2014; Kiefte-de Jong et al. 2014; Maijo et al. 2014). The metabolism of different nutrients may involve genes from different signaling and metabolic pathways (Barzilai et al. 2012). Genetic variants that contribute to variability in health and lifespan in response to consumption of a given spectrum of nutrients are likely to be detected in GWAS of human lifespan and other health and longevity related traits. Also, improvements in social and economic status provide better access to health care and high quality nutrition, leading to additional improvements in lifespan and survival.

All external factors discussed above dynamically interact with the aging processes in individuals comprising each human population to produce the age patterns of mortality rates for the various birth cohorts. As mentioned in "Which forces shape the age patterns of human mortality rates?", section a remarkable property of such interaction is that the resulting 
Fig. 2 An illustration of a decline in resistance to stresses with increasing age using Gompertz's model of human mortality evaluated for SSA life table data on the 1900-birth cohort, females. Each additional year of life lived after age 90 is associated with higher mortality risk than each additional year lived after age 80 . Equivalently, for each $y$, the annual increases in mortality risk are larger among 90-year old than among 80-year old individuals

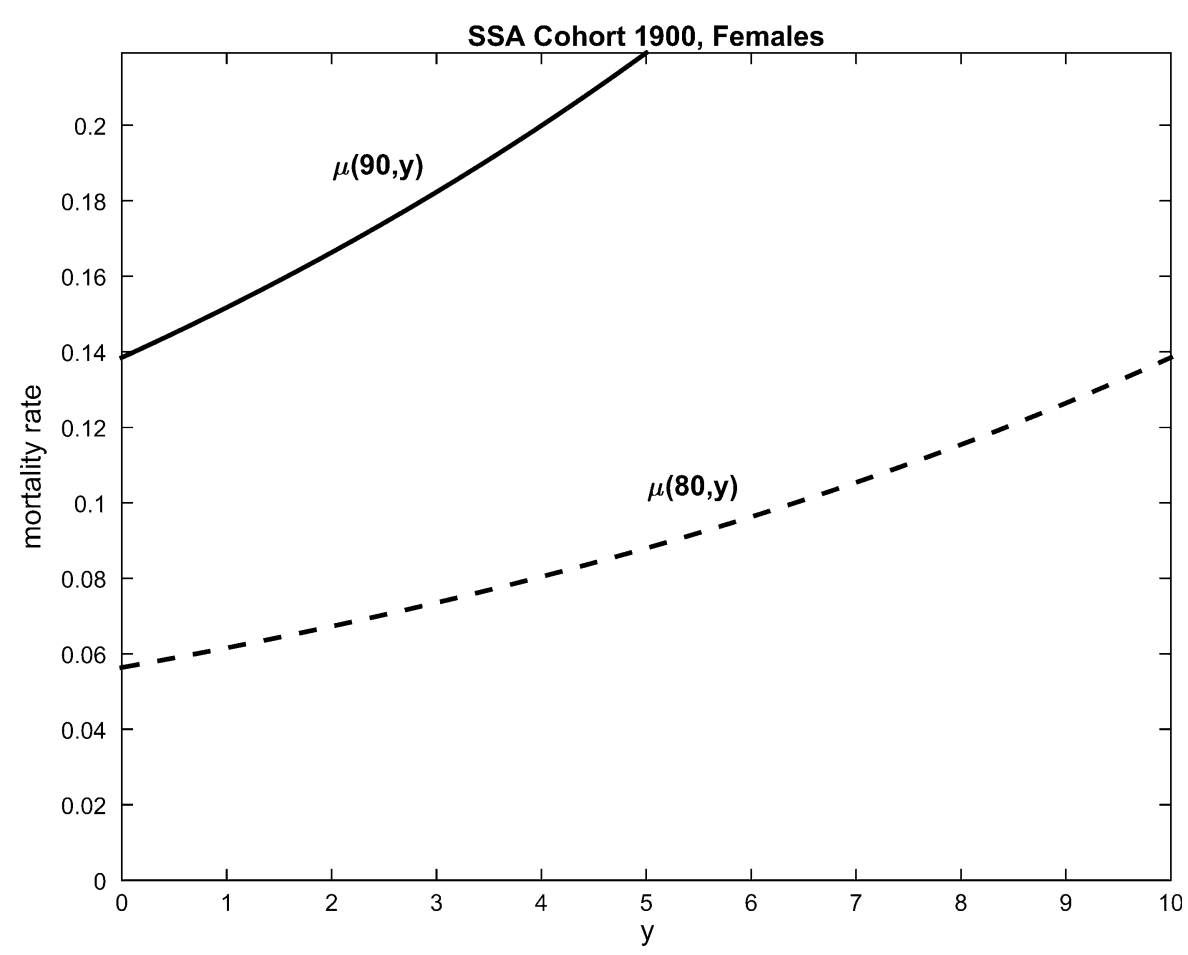

mortality rates between ages 30 and 85 always follow the Gompertz $\mu(x)=a e^{b x}$ or Gompertz-Makeham $\mu(x)=c+a e^{b x}$ laws. Time trends in survival improvement affect the parameters of these curves. These changes were not arbitrary but followed remarkable regularity: the parameter $c$ declined during all years. The changes in the parameters $a$ and $b$ during the first half of the 20th century showed strong negative correlations in all developed countries with parameter $a$ declining, and parameter $b$ increasing. Thereafter, parameter $b$ stopped increasing, parameter $a$ continued declining, and no correlations were observed between $a$ and $b$ (Yashin et al. 2001a, 2002a).

\section{Mortality and aging: how are they related?}

The connection between individual aging and mortality is well understood and widely discussed among demographers and bio-gerontologists (Atkins et al. 2014; Doubal and Klemera 1990; Economos 1982; Heller et al. 1998; Jazwinski 2002; Manton and Yashin 2000; Riggs 1992; Yashin et al. 2002b). Aging was associated with the decline in resistance to stresses in
Drosophila (Semenchenko et al. 2004). The connection between stress resistance, aging, and longevity has been addressed in many experimental studies of aging with laboratory animals (Cypser and Johnson 2002; Epel and Lithgow 2014; Lithgow and Walker 2002; Parsons 2002; Savory et al. 2014; Wu et al. 2008). Some authors use the terms "decline in homeostatic capacity" or "homeostenosis" as synonyms for the decline in stress resistance and resilience with age (Shega et al. 2012).

The Gompertz-Makeham function can be represented in a manner that emphasizes the role of stress resistance in the connection between aging and mortality. For this purpose, we first rewrite the function in the form $\mu(x)=c+a e^{b x_{0}} e^{b\left(x-x_{0}\right)}$ and then consider it as a function of two variables $\mu\left(x_{0}, y\right)=c+a e^{b x_{0}} e^{b y}$ where $x_{0}$ is some selected baseline age for an individual, and $y=x-x_{0}$ is the number of years lived after that selected age. An important property is that for a given value of $y$ the increment of mortality risk increases with increasing $x_{0}$ (Fig. 2).

Figure 2 shows that (i) the number of years lived after a given age can be considered as a risk factor for individuals who survived to this age; (ii) the risk 
function is $J$-shaped ( $U$ - or $J$-shaped risk functions are typical of many other risk factors); (iii) the $J$-shaped risk function gets narrower with increasing baseline age, $x_{0}$. The latter means that the price (measured in the increment of mortality risk) for the same deviation of this risk factor (the number of years lived after the selected baseline age) from zero increases with increasing age. Although the Gompertz and Gompertz-Makeham mortality models clearly represent this phenomenon, they do not explicitly describe the details of the dynamic interactions between individual aging and environmental stresses. An important step in this direction was taken by Strehler and Mildvan (1960).

Strehler and Mildvan model of mortality and aging

In parallel with demographic efforts focused on developing and implementing models of survival in heterogeneous populations with a hypothetical variable describing hidden heterogeneity, researchers in the field of aging recognized the crucial roles of individual aging-related changes in biomarkers characterizing metabolic and other functioning in mortality risk. The reviews of physiological studies of aging carried out in the middle of the last century showed that physiological parameters characterizing many human biological capacities tended to decline almost linearly with age. To reconcile a linear aging-related decline in biological capacities with exponential increases in the rate of mortality, Strehler and Mildvan (1960) proposed their model of aging and mortality (SM-model).

Gompertz's parameters characterize interaction between aging and environment

In the SM-model, death is viewed as resulting from the interaction of an aging-related decline in each organism's "vitality" function with a random process of external or internal challenges that are transformed to a process of energy demands for the organism. The hypothetical vitality function can be interpreted here as a measure of stress resistance. According to the SM-model, the death rate at a given age is proportional to "the frequency of stresses which surpass the ability of a subsystem to restore the initial conditions" at that age. The authors showed that, under such an assumption, the exponential increase in mortality
(Gompertz's curve) results from the linear decline in vitality. The model allowed them to explain the negative correlation between the two parameters of the Gompertz curve (SM-correlation) observed in empirical studies of the age patterns of mortality rates. The rectangularization pattern of survival improvement during the first half of the 20th century in developed countries was in accordance with the SM correlation, as predicted by the SM-model. These changes were linked to a decline in the frequencies and average magnitudes of stresses of life experienced by subsequent population cohorts (Yashin et al. 2001a, 2002a). Further development of this model can be found in ( $\mathrm{Li}$ et al. 2013; Zheng et al. 2011). These extensions accommodated the later patterns of survival improvement that corresponded to almost parallel shift of survival curve to the right ( $\mathrm{Li}$ and Anderson 2015). The importance of these studies lies in the fact that survival improvements can be explained by interactions between external challenges and internal agingrelated changes. Several useful insights into the genetics of human longevity follow from these analyses.

Genetics of stress resistance and longevity

A rectangularization pattern of survival improvement was also exhibited among individuals in the original Framingham Heart Study (FHS) cohort grouped by the number of longevity alleles that they carried (Yashin et al. 2012b). Since the environmental conditions were the same for each group, the SM model linked better survival with higher initial values of the vitality function, suggesting that exceptional survival was likely to have a genetic background. The more longevity alleles that were carried by study participants the higher was their initial stress resistance (the initial value of the vitality function). In terms of genetic functions, the resistance to stresses is associated with DNA repair capacity, redundancy, and other functions that increase the resilience, or robustness, of each organism. A useful illustration of how increased resilience can influence survival derives from the model of saving lives (Vaupel and Yashin 1987). An increase in the "number of lives being saved" for individuals in the population is interpreted as an increase in redundancy: for each life lost (premature death), the decedent has one or more "redundant" 
lives, depending on the relevant advances in medical technology (Yashin et al. 2012b).

The use of a measure of stress resistance (vitality) that is only hypothetical is a critical limitation of the SM model. To develop this concept for more realistic investigations, additional information and model extensions are required. The most promising sources of new information are the individual-level longitudinal data files currently being assembled at multiple sites under NIH funding. Longitudinal data on aging, health, and longevity are needed to study the connections between mortality and resistance to stresses when such stresses are represented as deviations of physiological variables from their normal values. Genetic data are needed for participants in longitudinal studies to analyze the roles of genetic factors in such connections. Both types of data are collected routinely in many longitudinal studies (e.g., FHS, Long Life Family Study, Health and Retirement Study, etc.). Comprehensive analyses of such data can be performed using the new integrative mortality models (Yashin et al. 2011) discussed in the next section.

\section{Integrative mortality models}

How can one develop a mortality model whose parameters characterize aging-related declines in health and physiological/biological functioning and other factors that contribute to mortality risk? To address this question one first has to specify a list of health disorders whose effects on mortality are to be investigated, identify potential influential factors (e.g., genetic and non-genetic), and a set of biomarkers that could properly represent declines in physiological/ biological functioning with increasing age. Then one has to find a proper functional form for the conditional hazard rate to link these variables with mortality risks. The dynamic mechanisms of changes in health, physiological variables, and other biomarkers with increasing age should be described as well. Such a description should include the possibility of external and internal challenges, adaptive and compensatory responses of organisms to these challenges, as well as stochastic influences.

Stochastic process models of human mortality and aging

Although the approaches based on the fixed frailty model are flexible and useful in many applications, their applicability to analyses of aging is limited because they do not take into account important variables and dynamic mechanisms of aging-related changes. Analyses of aging-related changes in physiological variables require a model that represents the individual age trajectories for these variables. Such a representation is illustrated in Fig. 3.

The scheme in Fig. 3 is equivalent to the following stochastic differential equation with respect to the physiological variable $Y_{t}(t$ is age, $G$ denotes genotype/allele):

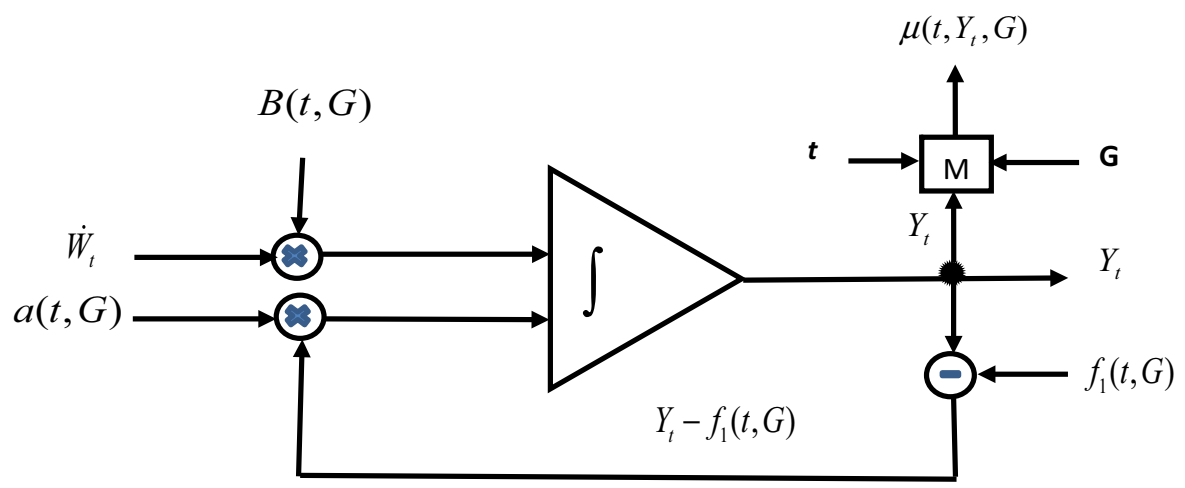

Fig. 3 Scheme illustrating the mechanism that regulates age trajectories of individual physiological variables in the stochastic process model of human mortality and aging. The white noise $W_{t}$, enhanced by the coefficient $B(t, G)$ and the difference between the value of the physiological variable $Y_{\mathrm{t}}$ and the effect of allostatic adaptation $f_{l}(t, G)$ multiplied by the negative feedback coefficient $a(t, G)$ are added and integrated to produce the value of the physiological variable $Y_{\mathrm{t}}$ at age $t$. The variable $Y_{\mathrm{t}}$ is used in the feedback regulation mechanism. Taken together with age, $t$, and genetic background, $G$, the variable $Y_{\mathrm{t}}$ is used for evaluating the mortality risk $\mu\left(t, Y_{t}, G\right)$ at age $t$ 
$d Y_{t}=a(t, G)\left(Y_{t}-f_{1}(t, G)\right) d t+B(t, G) d W_{t}$,

This equation is solved using the initial condition $Y_{t_{0}}=Y_{0}$. The coefficients $a(t, G), f_{l}(t, G)$, and $B(t, G)$ characterize adaptive capacity, the effect of allostatic adaptation, and the strength of the stochastic component that modulates the effects of the Wiener process $\left(W_{t}\right)$, respectively. Adaptive capacity is an important characteristic of aging because it tends to decline with age (homeostenosis) (Lund et al. 2002; Troncale 1996). The effect of allostatic adaptation integrates the influence of many external and internal challenges on physiological variable and it is used for evaluating allostatic load. Note that, although the notions of the effect of allostatic adaptation and allostatic load are conceptually close to those discussed in Seeman et al. (2001) and Karlamangla et al. (2006), our mathematical description looks different from theirs because it is adapted to the structure of our model.

Allostatic load is defined as a difference between the effect of allostatic adaptation and the age-specific physiological norm. The need for conceptualizing the notion of norm has been widely discussed (Lewington et al. 2002; Palatini 1999; Westin and Heath 2005). It is logical to define such a norm as the value of the physiological variable that minimizes the $U$-shaped mortality risk at a given age; in this case, the norm represents the optimal value of the variable. The use of the quadratic function for mortality risks allows us to capture the decline in stress resistance with age (Yashin et al. 2012a). The age dynamics of influential factors (e.g., physiological variables) in connection with mortality risks have been described using a stochastic process model of human mortality and aging (Woodbury and Manton 1977). Recent extensions of this model incorporating hidden biomarkers of aging into the model's structure have been used in analyses of FHS longitudinal data on aging, health, and longevity; see (Yashin et al. 2012a) and the references therein.

The $U$-shaped mortality risk captures the decline in stress resistance

Many epidemiological studies provide evidence of $U$ or J-shaped risks as functions of different physiological characteristics of health (Allison et al. 1997; Boutitie et al. 2002; Kulminski et al. 2008; Kuzuya et al. 2008; Mazza et al. 2007; Okumiya et al. 1999; Protogerou et al. 2007; Troiano et al. 1996; Witteman et al. 1994). Therefore, the use of such quadratic (U- or J- shaped) hazards in the analytic models is biologically meaningful (Yashin et al. 2012a). The implications of using a quadratic form for the conditional hazard rate in analyses of aging and longevity from longitudinal data are illustrated in Fig. 4.

Figure 4 corresponds to the following representation of the hazard rate $\mu\left(t, Y_{t}, G\right)$ for individuals at age $t$ :

$$
\begin{aligned}
\mu\left(t, Y_{t}, G\right)= & \mu_{0}(t, G)+\left(Y_{t}-f_{0}(t, G)\right)^{*} Q(t, G)\left(Y_{t}\right. \\
& \left.-f_{0}(t, G)\right)
\end{aligned}
$$

Here $\mu_{0}(t, G)$ is a genotype-specific baseline hazard, $f_{0}(t, G)$ is the genotype-specific physiological norm, $Q(t, G)$ is a genotype-specific matrix regulating the width of the paraboloid (Fig. 4) at different times of life, and the symbol "*" denotes transposition. The advantage of using this approach for analysis of longitudinal data is that it allows all of the concepts and mechanisms of aging-related changes in physiological variables and other biomarkers mentioned above to be incorporated into the model under a common framework. The version of the stochastic process model for analyses of genetic data was developed in (Arbeev et al. 2009). This model and its extensions are described by a random Markov process that satisfies a diffusion type stochastic differential equation. This stochastic process is stopped at the random time associated with each individual's lifespan. The quadratic hazard assumption for the conditional mortality risk, given covariate values and certain regularity conditions, guarantees a Gaussian property for the conditional distribution of the covariate values at each given age. This property allows agingrelated changes of the covariates to be described parsimoniously in terms of the first two conditional moments of a multidimensional Gaussian distribution. For each given age, these conditional moments characterize the distributions of physiological variables and other biomarkers among the members of the population cohort who survive to this age.

Estimating genetics of stress resistance from longitudinal data

One advantage of using longitudinal data in studies of genetic influences on longevity is the possibility of constructing empirical survival functions and age trajectories of physiological variables for the sub- 
Fig. 4 Illustration of hypothetical twodimensional U-shaped mortality risks (quadratic hazards) considered as a function of two risk factors $\mathrm{Y}_{1 \mathrm{x}}$ and $\mathrm{Y}_{2 \mathrm{x}}$ (e.g., physiological variables) for 30- and 80-year old individuals. The width of each paraboloid characterizes resistance to stresses for the young and old individuals. The coordinates of the minimal values of each paraboloid correspond to physiological norms. The model allows the normal values to be different at different ages. Individual physiological states are allowed to change with increasing age

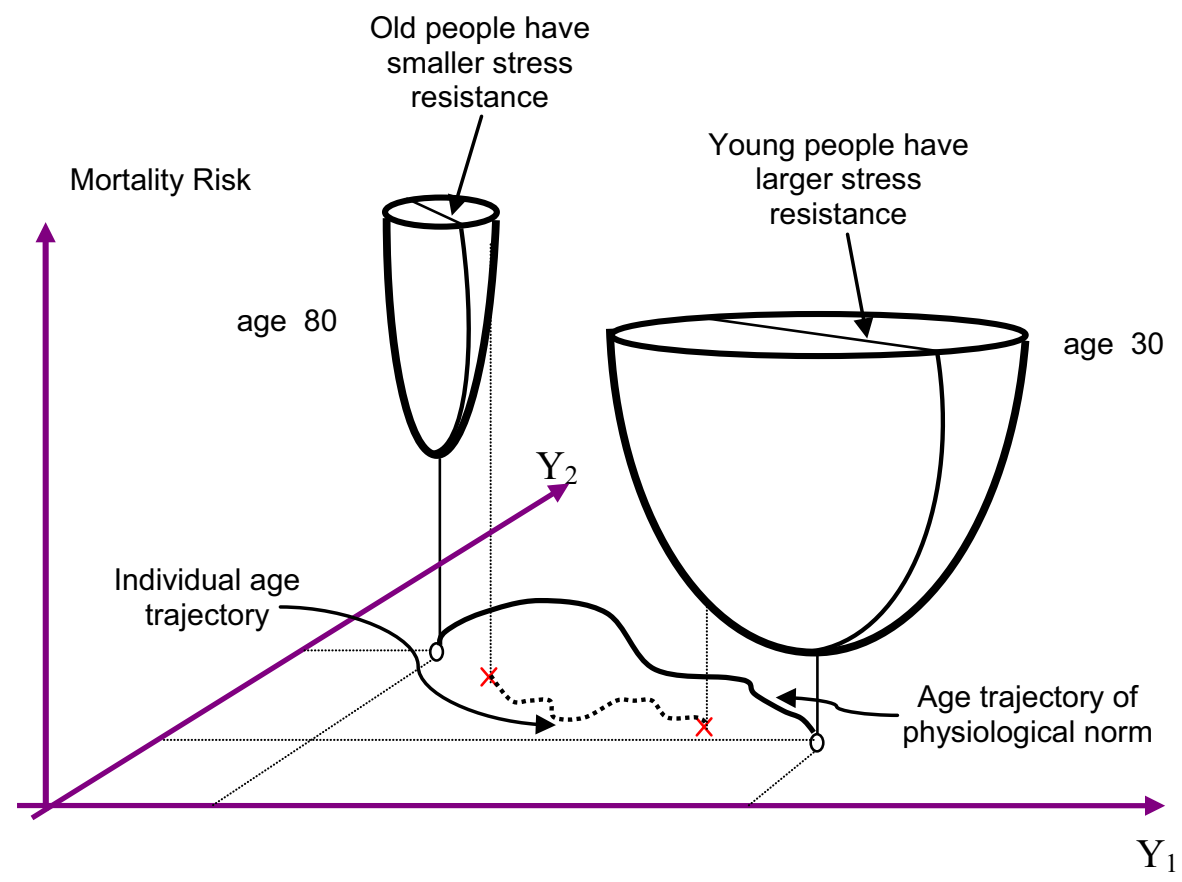

cohorts of carriers and non-carriers of alleles or genotypes detected in association studies (Yashin et al. 2013a). Such possibilities do not exist in case-control association studies when only two age groups of individuals are compared. The use of integrative mortality models opens an additional opportunity for studying how genetic factors associated with lifespan influence age trajectories of hidden biomarkers of aging, such as effects of allostatic adaptation, stress resistance, adaptive capacity, physiological norm, allostatic load, etc. These biomarkers are usually not measured in longitudinal studies. However, they modulate mortality risk and may influence age trajectories of other variables measured in the study. One such hidden biomarker characterizes resistance to stresses. In the integrative mortality models, this variable is represented by the coefficients describing the U-shaped mortality risk as a function of observed covariates. In the one-dimensional case, such mortality risk is represented by the following quadratic function $\mu\left(t, Y_{t}, G\right)=\mu_{0}(t, G)+\mu_{1}(t, G)\left(Y_{t}-f_{0}(t, G)\right)^{2}$, where the notation $\mu_{1}(t, G)$ is used instead of $Q(t, G)$ in (2). The coefficient $\mu_{1}(t, G)$ characterizes stress resistance. It regulates the width of the U-shaped risk function (Fig. 4). When the value of this coefficient is small (the U-shape is wide) the risk function is less sensitive to small deviations of $Y_{t}$ from the norm.
This is the case of better stress resistance. When the value of this coefficient is high (the $\mathrm{U}$-shape is narrow) the risk function is sensitive to small deviations of $Y_{t}$ from the norm. This is the case of worse stress resistance. The changes in stress resistance over age are illustrated in Fig. 5, which shows the graphs of the quadratic components of the conditional hazards for serum cholesterol, separately for members of the FHS original cohort who were carriers and non-carriers of the APOE e4 allele.

Stress resistance (i.e., the width of the U-shaped mortality risk) among carriers of the APOE e4 allele declined faster with age than among non-carriers of this allele.

\section{Discussion}

From the statistical point of view human lifespan can be represented as a nonnegative random variable characterized by some probability distribution. Because influential factors may affect this distribution in thousands of different ways, many patterns of survival changes in response to changing environment are possible. Nonetheless, the changes in lifespan distribution during the last two to three centuries followed only two basic patterns. The first was 

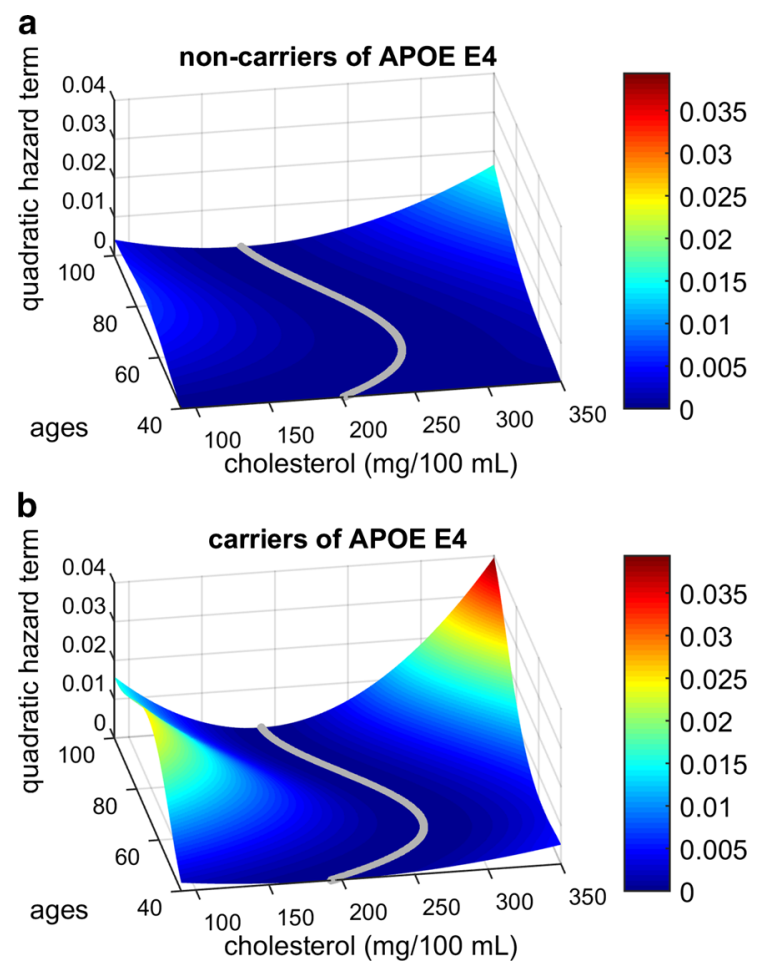

Fig. 5 The changes in the U-shapes of mortality risks with increasing age for carriers (a) and non-carriers (b) of the APOE e4 allele evaluated from data on serum cholesterol and survival for individuals from the original FHS cohort

associated with rectangularization of the survival curve (described by the SM correlation between the two Gompertz parameters $a$ and $b$ ). Then, in the middle of the 20th century, the rectangularization was replaced by another pattern: an almost parallel shift of the entire survival curve to the right. This second pattern was characterized by an increase in the right tail of the lifespan distribution, which raised an important question: Did people with extreme longevity from distinct birth cohorts, i.e., who had lifespans from these right tails, have the same genetic backgrounds? One answer is "no" because lifespan is a multifactorial trait determined by genetic and nongenetic (environmental) factors, and human environments experienced substantial changes during the last century. At the same time, the fact that mechanisms of genetic regulation of human aging and longevity are evolutionary conserved indicates high possibility of detecting associations with genes from corresponding signaling and metabolic pathways that suppose function in different environments.

Exposures to different types of environments may involve different genes and molecular biological pathways affecting lifespan regulation; hence, sets of genetic variants detected in GWAS of human longevity in independent populations may differ if people in these populations were exposed to different environments. Since exposures of populations to environmental conditions are hard to measure, one can expect difficulties in replication of findings using independent populations. If genetic factors involved in survival responses are sensitive to the spectrum of external challenges, one can expect that genetic variants contributing to exceptional longevity a hundred or more years ago may not be responsible for such traits today (Yashin et al. 2001b). The concept of the "norm of reaction" can help us better understand what information is needed to clarify the effects of gene/ environment $(\mathrm{GxE})$ interactions on lifespan.

The concept of the norm of reaction of a genotype with respect to a given phenotype (Aubin-Horth and Renn 2009; Nussey et al. 2007; Scheiner and Holt 2012) describes the pattern of phenotypic variation of a single genotype across a range of environmental conditions. For each given genotype, there is a curve that relates the contribution of environmental variation to observed phenotypic variation. The concept of the norm of reaction also clarifies how carriers of two different genotypes may produce different phenotypic responses to the same environmental conditions (Flatt 2014). They also may have different responses to the same changes in these conditions over time.

The estimates of the norm of reaction for human health and longevity traits (as well as for many other traits) are difficult to obtain using data from observational longitudinal studies. This is because thousands of external factors may contribute to the variability of these traits and many exposures of study subjects to such factors are difficult to measure due to the large numbers of such factors, the dynamic nature of exposures to them, the high cost related to their identification and measurement, etc. How, then, can one evaluate the long-term effects of genetic factors on health and longevity using limited information about environmental exposures of study subjects? Fortunately, even limited information is useful for clarifying the dynamic connections among, aging, health and longevity. The notion of allostatic adaptation and allostatic load incorporated into the integrative mortality models can help in addressing this issue for the 
case of many unobserved influential factors using longitudinal data for several generations of people (Yashin et al. 2012a).

Changes in the spectrum, frequencies, and magnitudes of external stresses affecting individuals may induce changes in the biological mechanisms underlying their genetic responses. One can expect that biological responses to the same external challenges may involve different sets of genes in individuals having distinct genetic backgrounds. Such responses may also differ at different periods of persons' lives because of aging-related changes or histories of exposure to different environments. Genetic variants that were involved in lifespan regulation at different age intervals of human life are also likely to make contributions to lifespan variability. These variants are likely to be detected in genetic association studies of lifespan.

Additional biodemographic information for genetic analyses of human aging, health, and longevity could come from recognizing that human populations consist of families and family members, i.e., groups of individuals who share many genetic and non-genetic factors. For this reason the lifespans and other complex traits of family members are likely to be dependent variables. An important class of extended fixed frailty models describes survival in related individuals (e.g., twins, sibs, and other relatives) (Yashin et al. 1995). Multivariate survival models were used for estimating the heritability of individual susceptibility to death (Yashin and Iachine 1995) as well as the heritability of mortality by cause (Wienke 2010). The dependence among individuals is responsible for many interesting properties observed in studies of aging, health, and longevity. In particular, the fact that extreme longevity tends to run in families is a consequence of a positive correlation among lifespans of family members. This property demonstrates the high potential of multivariate survival models for studying factors and mechanisms affecting exceptional survival in families (Yashin and Iachine 1999a, b). Therefore, the estimates of individual frailties can be used as new, measured traits for genetic analyses of human longevity. Numerical values of these traits can be estimated for individuals with and without censored lifespans.

The multivariate survival models may also be used for studying dependent events (e.g., development of co-morbidity and multi-morbidity) in elderly individuals. The health problems of the elderly are associated with the presence of multiple chronic diseases that have a number of common risk factors and therefore are not independent, in contrast to infectious diseases. Dependence among diseases means that any action (preventive or treatment) that involves changes in the risk of one disease may also affect (positively or negatively) the risks of other diseases. So any strategy for the reduction of disease burden or eradication of some target disease has to take the underlying mechanisms of disease dependence into account (Yashin et al. 1986). Evidence for the trade-offs between cancer and other diseases (such as heart disease, stroke, diabetes, Alzheimer's and Parkinson's diseases, and asthma) as well as the connection between cancer and aging changes were discussed in (Yashin et al. 2009). Note that the meaning of the term heterogeneity as used by many genetic epidemiologists differs from the meaning in demographic and epidemiological studies. In genetic epidemiology this term refers to the situation where the same value of a trait can be determined by several hidden genetic (or non-genetic) factors. Many such situations can be well described using multivariate heterogeneity variables.

Personalized prevention and treatment requires an understanding of the long-term consequences of the available interventions. It is well understood that increasingly efficient and effective strategies for maintaining long and healthy life will have to use information about each person's genetic background. It is also well known that lifespan and healthy lifespan are multifactorial traits that are subject to the dynamic influences of non-genetic factors during the life course. Better understanding of how genetic and non-genetic factors dynamically interplay with each other during the aging process to form health and longevity traits, and of which biomarkers and processes are involved in mediation of these influences, is needed to develop personalized approaches to prevention and treatment of aging-related diseases. This means that information on a person's genetic background alone is not sufficient to efficiently maintain healthy and long life. For successful maintenance of people's health, what is needed are good estimates of the long-term effects of genetic and non-genetic factors as well as GxE interactions on health and survival outcomes. This, in turn, requires an understanding of how the dynamic effects of persistent external disturbances (e.g., medications, diet, emotional or other stresses of life, exposure to 
environmental contaminants, etc.) on health and survival outcomes are integrated and how such integration may differ for individuals with different genetic backgrounds. An important insight into personalized aspects of prevention and treatment is that the effects of genetic factors on lifespan and healthy lifespan are not fixed for each individual, as assumed, say, in models used in heritability estimates. These effects may vary greatly depending on an individual's history of environmental exposures, his/her age, genetic background, etc.

How do environmental changes influence aging, health, and longevity traits of individuals? It is clear that the changes in survival in Fig. 1 resulted from the interplay among external conditions, genetic factors, ontogenetic, senescent, and other processes in individuals comprising the specific human populations. At first glance, it may appear that such changes have little or nothing to do with genes, because it is quite unlikely that the genetic backgrounds of the countries' residents changed substantially during the relatively short time periods involved. This point of view, however, is oversimplified because it assumes the existence of biological mechanisms through which the environment can modulate phenotypic traits-without involving genes. In reality, genes are always involved in such changes: they transform the signals from external challenges into the organism's biological and, ultimately, health/survival responses. The specific genes involved in forming these responses are likely to be detected in GWAS of human aging, health, and longevity. Thus, the genetic mechanisms involved in transforming environmental signals into metabolic and other biological responses account for the influences of external challenges on phenotypic traits.

The changes in survival in Fig. 1 demonstrate the effects of at least three types of GxE interactions on lifespan. One type (e.g., better living and working conditions) reduced the frequency and average magnitude of environmental stresses. The second type enhanced stress resistance and resilience of human organisms through advances in medicine and better health care. The third type improved individual stress resistance in response to better quality of nutrition and other components of metabolic processes. For all three cases, exposures to new conditions may have activated new genes and inactivated others. The genetic variants related to genes that interacted with different external conditions and contributed to changes in lifespan during an individual's life course are likely to be detected in GWAS of human aging and lifespan. One question remains for further research: Why do the populations of the two countries in Fig. 1 have similar age patterns of survival improvement despite different genetic backgrounds of their individuals, different cultural traditions, climate, and other environmental and living conditions?

Pleiotropic associations of genetic variants

The genetic connections between aging and diseases imply that genes involved in the regulation of agingrelated processes could also be involved in regulating not just one age-related disease, but perhaps a major subset of such diseases (Butler et al. 2008; Martin et al. 2007). If true, then aging-related genes should be among those predisposing to multiple health traits. The accumulating evidence indicates that genes with pleiotropic effects are likely to be involved in regulating fundamental biological processes in an organism (Chavali et al. 2010; Goh et al. 2007). Better understanding of the underlying mechanisms of pleiotropy and the connections of these mechanisms with those regulating aging and lifespan will advance the rate of progress in extending health span and developing personalized medicine (Jain 2002).

The estimates of the effects of genetic factors on lifespan depend on many conditions, including individual genetic backgrounds, exposure to external and internal factors, health status, age, and others. To illustrate, consider an example of age dependence for which an initially harmful common genetic variant, i.e., a variant that increases mortality risk among young adults, may become neutral around ages 70 or 80 years and may manifest beneficial effects on survival thereafter-thereby contributing to living to 100 years. For this case, the genetic variants associated with exceptional longevity may not be rare: the initial frequency of such an allele can be substantially higher than $1 \%$. It may be smaller around age 70-80 and then increase again. Such age trajectories of genetic frequencies were actually observed in genetic studies of centenarians (Atzmon et al. 2006; Bergman et al. 2007; De Benedictis et al. 1998; Yashin et al. 1999). Unexpectedly high frequencies of genetic risk alleles among oldest-old individuals were also observed in other studies (Beekman et al. 2010; Rose et al. 2001; Ukraintseva et al. 2012). Many genetic variants have pleiotropic effects on several phenotypic 
traits. Taking these effects into account may improve the quality of genetic analyses (Bolormaa et al. 2014; Mills et al. 2014; Solovieff et al. 2013; van VlietOstaptchouk et al. 2013).

The improvement of our conceptual framework might substantially increase the efficiency of genetic analyses. Further development and implementation of the methods of systems biology in the analysis of data look promising (Yashin and Jazwinski 2014). Studying the effects of rare combinations of interacting common genetic variants (epistasis) or the absence of large numbers of harmful common variants that increase mortality risk at the old and the oldest-old ages may make substantial contributions to our understanding of exceptional longevity. Exceptional longevity may also result from beneficial effects of interactions between common variants and environmental factors (GxEinteraction effects). The continuing improvement in survival (Fig. 1) and unprecedented concurrent increases in the proportion of centenarians in developed countries provide strong evidence for age-specific $\mathrm{GxE}$ interaction effects on mortality risks. Many experts have offered (often controversial) opinions concerning the environmental factors responsible for these changes. Nonetheless, the details of the biological responses and mechanisms affecting the aging, health, and survival improvements still remain unknown.

The body of knowledge of various aspects of genetic influence on aging, health, and longevity continues to increase. These aspects include data on whole-genome sequencing, gene expression, epigenetics, etc. Such knowledge is gathered for individuals from longitudinal studies, case-control studies, patients in hospitals, volunteers, etc. Each new type of genetic data brings new information for studying how people age, how their health deteriorates, and how these changes affect lifespan. This information can be integrated and used to gain insight into alternative ways of slowing or postponing such health deterioration. Through analyses of these data, new roles of genetic factors in forming biological responses to external challenges will be elucidated. Questions regarding the dynamic interactions between external factors and biological mechanisms will be of crucial importance. Although dealing with such genetic data provides new opportunities for researchers, it does not automatically lead to understanding the connections between genetic factors and aging, health, and longevity traits; instead, the new opportunities create new challenges. The presence of many rare SNPs increases the number of statistical tests, which aggravates the problem of correcting for multiple testing. Dealing with low allelic frequencies requires larger sample sizes, which may be difficult for human studies. The methodologies for genetic analyses have to be adequately adjusted as well (Asimit and Zeggini 2010; Basu and Pan 2011; Feng et al. 2015; Feng and Zhu 2012; Lee et al. 2014b).

The need for developing effective strategies for maintaining good health for the elderly over longer time periods motivates the quest for deeper insights into the nature of individual aging processes and their relationships with health and survival outcomes. This requires information not only on individuals' genetic backgrounds but also on personalized aspects of genetic interactions with external forces and conditions, as well as on genetic and non-genetic influences on health and survival outcomes, and a better understanding of how those influences are mediated by physiological variables and other biomarkers. The data containing such information and the corresponding advanced methods needed for their analyses are being developed and made available to the research community. The methods of systems biology combined with integrative statistical modeling and analyses of longitudinal data on genotyped individuals are likely to make substantial contributions to clarifying the connections among aging, health, and longevity.

Acknowledgments Research reported in this publication was supported by the National Institute on Aging of the National Institutes of Health under Award Numbers R01AG046860, P01AG043352, and P30AG034424. The content is solely the responsibility of the authors and does not necessarily represent the official views of the National Institutes of Health. The Framingham Heart Study is conducted and supported by the National Heart, Lung, and Blood Institute (NHLBI) in collaboration with Boston University (Contract No. N01-HC25195). This manuscript was not prepared in collaboration with investigators of the Framingham Heart Study and does not necessarily reflect the opinions or views of the Framingham Heart Study, Boston University, or NHLBI. Funding for SHARe Affymetrix genotyping was provided by NHLBI Contract N02HL-64278. SHARe Illumina genotyping was provided under an agreement between Illumina and Boston University. The authors thank Debra Fincham for help in preparing this paper for publication.

\section{References}

Aalen OO (1994) Effects of frailty in survival analysis. Stat Methods Med Res 3:227-243 
Aalen OO, Valberg M, Grotmol T, Tretli S (2014) Understanding variation in disease risk: the elusive concept of frailty. Int J Epidemiol. doi:10.1093/ije/dyu192

Abbring JH, Van den Berg GJ (2007) The unobserved heterogeneity distribution in duration analysis. Biometrika 94:87-99. doi:10.1093/biomet/asm013

Abelson PH (1993) Improvements in health care. Science 260:11

Akushevich I, Kravchenko J, Ukraintseva S, Arbeev K, Kulminski A, Yashin AI (2013) Morbidity risks among older adults with pre-existing age-related diseases. Exp Gerontol 48:1395-1401. doi:10.1016/j.exger.2013.09.005

Alfin-Slater RB (1979) Nutrition and aging: introduction Federation proceedings 38:1993

Allison DB, Faith MS, Heo M, Kotler DP (1997) Hypothesis concerning the U-shaped relation between body mass index and mortality. Am J Epidemiol 146:339-349

Arbeev KG et al (2009) Genetic model for longitudinal studies of aging, health, and longevity and its potential application to incomplete data. J Theor Biol 258:103-111. doi:10. 1016/j.jtbi.2009.01.023

Arbeev KG, Ukraintseva SV, Arbeeva LS, Akushevich I, Kulminski AM, Yashin AI (2011) Evaluation of genotypespecific survival using joint analysis of genetic and nongenetic subsamples of longitudinal data. Biogerontology 12:157-166. doi:10.1007/s10522-010-9316-1

Asimit J, Zeggini E (2010) Rare variant association analysis methods for complex traits. Annu Rev Genet 44:293-308. doi:10.1146/annurev-genet-102209-163421

Atkins JL, Whincup PH, Morris RW, Lennon LT, Papacosta O, Wannamethee SG (2014) Sarcopenic obesity and risk of cardiovascular disease and mortality: a population-based cohort study of older men. J Am Geriatr Soc 62:253-260. doi:10.1111/jgs.12652

Atzmon G, Rincon M, Schechter CB, Shuldiner AR, Lipton RB, Bergman A, Barzilai N (2006) Lipoprotein genotype and conserved pathway for exceptional longevity in humans. PLoS Biol 4:e113. doi:10.1371/journal.pbio.0040113

Aubin-Horth N, Renn SC (2009) Genomic reaction norms: using integrative biology to understand molecular mechanisms of phenotypic plasticity. Mol Ecol 18:3763-3780. doi:10.1111/j.1365-294X.2009.04313.x

Baird RD, Caldas C (2013) Genetic heterogeneity in breast cancer: the road to personalized medicine? BMC Med 11:151. doi:10.1186/1741-7015-11-151

Barzilai N, Rennert G (2012) The rationale for delaying aging and the prevention of age-related diseases. Rambam Maimonides Med J 3:e0020. doi:10.5041/rmmj.10087

Barzilai N, Huffman DM, Muzumdar RH, Bartke A (2012) The critical role of metabolic pathways in aging. Diabetes 61:1315-1322. doi: $10.2337 / \mathrm{db} 11-1300$

Basu S, Pan W (2011) Comparison of statistical tests for disease association with rare variants. Genet Epidemiol 35:606619. doi:10.1002/gepi.20609

Beekman M et al (2010) Genome-wide association study (GWAS)-identified disease risk alleles do not compromise human longevity. Proc Natl Acad Sci USA 107: 18046-18049. doi:10.1073/pnas.1003540107

Beltran-Sanchez H, Crimmins EM, Finch CE (2012) Early cohort mortality predicts the rate of aging in the cohort: a historical analysis. J Dev Orig Health Dis 3:380-386. doi:10.1017/s2040174412000281

Bergman A, Atzmon G, Ye K, MacCarthy T, Barzilai N (2007) Buffering mechanisms in aging: a systems approach toward uncovering the genetic component of aging. PLoS Comput Biol 3:e170. doi:10.1371/journal.pcbi.0030170

Bolormaa $S$ et al (2014) A multi-trait, meta-analysis for detecting pleiotropic polymorphisms for stature, fatness and reproduction in beef cattle. PLoS Genet 10:e1004198. doi:10.1371/journal.pgen.1004198

Bosma-den Boer MM, van Wetten ML, Pruimboom L (2012) Chronic inflammatory diseases are stimulated by current lifestyle: how diet, stress levels and medication prevent our body from recovering. Nutr Metab. doi:10.1186/17437075-9-32

Boutitie F, Gueyffier F, Pocock S, Fagard R, Boissel JP (2002) $\mathrm{J}$-shaped relationship between blood pressure and mortality in hypertensive patients: new insights from a meta-analysis of individual-patient data. Ann Intern Med 136:438-448

Broer L et al (2015) GWAS of longevity in CHARGE consortium confirms APOE and FOXO3 candidacy. J Gerontol A Biol Sci Med Sci 70:110-118. doi:10.1093/gerona/glu166

Bunker JP (2001) The role of medical care in contributing to health improvements within societies. Int $\mathrm{J}$ Epidemiol 30:1260-1263

Butler RN et al (2008) New model of health promotion and disease prevention for the 21st century. BMJ 337:a399

Cai D et al (2015) A correlation between diet and longevity characterization by means of element profiles in healthy people over 80 years from a chinese longevous region. Biol Trace Elem Res 165(1):18-29. doi:10.1007/s12011-015-0233-7

Calabrese V, Cornelius C, Cuzzocrea S, Iavicoli I, Rizzarelli E, Calabrese EJ (2011) Hormesis, cellular stress response and vitagenes as critical determinants in aging and longevity. Mol Aspects Med 32:279-304. doi:10.1016/j.mam.2011. 10.007

Carey JR, Liedo P, Orozco D, Vaupel JW (1992) Slowing of mortality rates at older ages in large medfly cohorts. Science 258:457-461

Carnes BA, Olshansky SJ (2001) Heterogeneity and its biodemographic implications for longevity and mortality. Exp Gerontol 36:419-430

Chavali S, Barrenas F, Kanduri K, Benson M (2010) Network properties of human disease genes with pleiotropic effects. BMC Syst Biol 4:78. doi:10.1186/1752-0509-4-78

Chedraui P, Perez-Lopez FR (2013) Nutrition and health during mid-life: searching for solutions and meeting challenges for the aging population. Climacteric 16(Suppl 1):85-95. doi:10.3109/13697137.2013.802884

Colgrove J (2002) The McKeown thesis: a historical controversy and its enduring influence. Am J Public Health 92:725-729

Crous-Bou M et al (2014) Mediterranean diet and telomere length in Nurses' Health Study: population based cohort study. BMJ 349:g6674. doi:10.1136/bmj.g6674

Cypser JR, Johnson TE (2002) Multiple stressors in Caenorhabditis elegans induce stress hormesis and extended longevity. J Gerontol A Biol Sci Med Sci 57:B109-B114

de Benedictis G et al (1998) Age-related changes of the $3^{\prime}$ APOB-VNTR genotype pool in ageing cohorts. Ann 
Hum Genet 62:115-122. doi:10.1046/j.1469-1809.1998. 6220115.x

de Magalhaes JP (2014) Why genes extending lifespan in model organisms have not been consistently associated with human longevity and what it means to translation research. Cell Cycle 13:2671-2673. doi:10.4161/15384101.2014.950151

Deelen J et al (2014) Genome-wide association meta-analysis of human longevity identifies a novel locus conferring survival beyond 90 years of age. Hum Mol Genet 23:4420-4432. doi:10.1093/hmg/ddu139

Doubal S, Klemera P (1990) Influence of aging rate change on mortality curves. Mech Ageing Dev 54:75-85

Economos AC (1982) Rate of aging, rate of dying and the mechanism of mortality. Arch Gerontol Geriatr 1:3-27

Eichler EE, Flint J, Gibson G, Kong A, Leal SM, Moore JH, Nadeau JH (2010) Missing heritability and strategies for finding the underlying causes of complex disease. Nat Rev Genet 11:446-450. doi:10.1038/nrg2809

Epel ES, Lithgow GJ (2014) Stress biology and aging mechanisms: toward understanding the deep connection between adaptation to stress and longevity. J Gerontol A Biol Sci Med Sci 69(Suppl 1):S10-S16. doi:10.1093/gerona/glu055

Evert J, Lawler E, Bogan H, Perls T (2003) Morbidity profiles of centenarians: survivors, delayers, and escapers. J Gerontol A Biol Sci Med Sci 58:232-237

Feng T, Zhu X (2012) Detecting rare variants. Methods Mol Biol 850:453-464. doi:10.1007/978-1-61779-555-8_24

Feng S et al (2015) Methods for Association Analysis and MetaAnalysis of Rare Variants in Families. Genet Epidemiol. doi:10.1002/gepi.21892

Flatt T (2014) Plasticity of lifespan: a reaction norm perspective. Proc Nutr Soc 73:532-542. doi:10.1017/s0029665114001141

Goh KI, Cusick ME, Valle D, Childs B, Vidal M, Barabasi AL (2007) The human disease network. Proc Natl Acad Sci USA 104:8685-8690. doi:10.1073/pnas.0701361104

Goldman DP, Cutler D, Rowe JW, Michaud PC, Sullivan J, Peneva D, Olshansky SJ (2013) Substantial health and economic returns from delayed aging may warrant a new focus for medical research. Health Aff 32:1698-1705. doi: $10.1377 /$ hlthaff.2013.0052

Hamerman D (2010) Can biogerontologists and geriatricians unite to apply aging science to health care in the decade ahead? J Gerontol A Biol Sci Med Sci 65:1193-1197. doi:10.1093/gerona/glq117

Heller DA, Ahern FM, Stout JT, McClearn GE (1998) Mortality and biomarkers of aging in heterogeneous stock (HS) mice. J Gerontol A Biol Sci Med Sci 53:B217-B230

Hougaard P (1995) Frailty models for survival data. Lifetime Data Anal 1:255-273

Hougaard P (1999) Multi-state models: a review. Lifetime Data Anal 5:239-264

Hougaard P, Myglegaard P, Borch-Johnsen K (1994) Heterogeneity models of disease susceptibility, with application to diabetic nephropathy. Biometrics 50:1178-1188

Jain KK (2002) Personalized medicine Curr Opin Mol Ther 4:548-558

Jazwinski SM (2002) Biological aging research today: potential, peeves, and problems. Exp Gerontol 37:1141-1146

Jazwinski SM (2005) The retrograde response links metabolism with stress responses, chromatin-dependent gene activation, and genome stability in yeast aging. Gene 354:22-27. doi:10.1016/j.gene.2005.03.040

Karlamangla AS, Singer BH, Seeman TE (2006) Reduction in allostatic load in older adults is associated with lower allcause mortality risk: MacArthur studies of successful aging. Psychosom Med 68:500-507. doi:10.1097/01.psy. 0000221270.93985 .82

Kesteloot H (1993) Nutrition and life expectancy of populations. Acta Cardiol 48:441-442

Kiefte-de Jong H, Mathers JC, Franco OH (2014) Nutrition and healthy ageing: the key ingredients. Proc Nutr Soc 73:249-259. doi:10.1017/s0029665113003881

Kirkwood TB (2015) Deciphering death: a commentary on Gompertz (1825) 'On the nature of the function expressive of the law of human mortality, and on a new mode of determining the value of life contingencies'. Philos Trans R Soc Lond B Biol Sci. doi:10.1098/rstb.2014.0379

Kirkwood TL, Kapahi P, Shanley DP (2000) Evolution, stress, and longevity. J Anat 197(4):587-590

Kulminski AM, Arbeev KG, Kulminskaya IV, Ukraintseva SV, Land K, Akushevich I, Yashin AI (2008) Body mass index and nine-year mortality in disabled and nondisabled older U.S. Individuals. J Am Geriatr Soc 56:105-110. doi:10. 1111/j.1532-5415.2007.01494.x

Kulminski AM et al (2011) Trade-off in the effects of the apolipoprotein E polymorphism on the ages at onset of CVD and cancer influences human lifespan. Aging Cell 10:533-541. doi:10.1111/j.1474-9726.2011.00689.x

Kuzuya M, Enoki H, Iwata M, Hasegawa J, Hirakawa Y (2008) J-shaped relationship between resting pulse rate and allcause mortality in community-dwelling older people with disabilities. J Am Geriatr Soc 56:367-368

Le Bourg E (2009) Hormesis, aging and longevity. Biochim Biophys Acta 1790:1030-1039. doi:10.1016/j.bbagen. 2009.01.004

Lee M, Ha ID, Lee Y (2014a) Frailty modeling for clustered competing risks data with missing cause of failure. Stat Methods Med Res. doi:10.1177/0962280214545639

Lee S, Abecasis GR, Boehnke M, Lin X (2014b) Rare-variant association analysis: study designs and statistical tests. Am J Hum Genet 95:5-23. doi:10.1016/j.ajhg.2014.06.009

Lewington S, Clarke R, Qizilbash N, Peto R, Collins R (2002) Age-specific relevance of usual blood pressure to vascular mortality: a meta-analysis of individual data for one million adults in 61 prospective studies. Lancet 360:1903-1913

Li T, Anderson JJ (2015) The Strehler-Mildvan correlation from the perspective of a two-process vitality model. Popul Stud 69:91-104. doi:10.1080/00324728.2014.992358

Li T, Yang YC, Anderson JJ (2013) Mortality increase in latemiddle and early-old age: heterogeneity in death processes as a new explanation. Demography 50:1563-1591. doi:10. 1007/s13524-013-0222-4

Link BG, Phelan JC (2002) McKeown and the idea that social conditions are fundamental causes of disease. Am J Public Health 92:730-732

Lithgow GJ, Walker GA (2002) Stress resistance as a determinate of C. elegans lifespan. Mech Ageing Dev 123:765-771

Lund J, Tedesco P, Duke K, Wang J, Kim SK, Johnson TE (2002) Transcriptional profile of aging in C-elegans. Curr Biol 12:1566-1573 
Lunetta KL et al (2007) Genetic correlates of longevity and selected age-related phenotypes: a genome-wide association study in the Framingham Study. BMC Med Genet 8(Suppl 1):S13

Mackenbach JP (1996) The contribution of medical care to mortality decline: McKeown revisited. J Clin Epidemiol 49:1207-1213

MacRae CA, Vasan RS (2011) Next-generation genome-wide association studies: time to focus on phenotype? Circ Cardiovasc Genet 4:334-336. doi:10.1161/CIRCGENETICS. 111.960765

Maijo M, Clements SJ, Ivory K, Nicoletti C, Carding SR (2014) Nutrition, diet and immunosenescence. Mech Ageing Dev 136-137:116-128. doi:10.1016/j.mad.2013.12.003

Manton KG, Yashin AI (2000) Mechanisms of aging and mortality: a search for new paradigms. Odense Monograph on Population Aging No. 7. Odense University Press, Odense

Martin GM, Bergman A, Barzilai N (2007) Genetic determinants of human health span and life span: progress and new opportunities. PLoS Genet 3:e125

Mazza A, Zamboni S, Rizzato E, Pessina AC, Tikhonoff V, Schiavon L, Casiglia E (2007) Serum uric acid shows a J-shaped trend with coronary mortality in non-insulin-dependent diabetic elderly people. The CArdiovascular STudy in the ELderly (CASTEL). Acta Diabetol 44:99-105. doi:10.1007/s00592-007-0249-3

McKeown T, Record RG, Turner RD (1975) An interpretation of the decline of mortality in England and Wales during the twentieth century. Popul Stud 29:391-422

Miller RA (2009) "Dividends" from research on aging-can biogerontologists, at long last, find something useful to do? J Gerontol A Biol Sci Med Sci 64:157-160. doi:10.1093/ gerona/gln062

Mills MG, Greenwood AK, Peichel CL (2014) Pleiotropic effects of a single gene on skeletal development and sensory system patterning in sticklebacks. EvoDevo 5:5. doi:10.1186/2041-9139-5-5

Morris BJ et al (2014) Genetic analysis of TOR complex gene variation with human longevity: a nested case-control study of American men of Japanese ancestry. J Gerontol A Biol Sci Med Sci. doi:10.1093/gerona/glu021

Newman AB et al (2010) A meta-analysis of four genome-wide association studies of survival to age 90 years or older: the Cohorts for Heart and Aging Research in Genomic Epidemiology Consortium. J Gerontol A Biol Sci Med Sci 65:478-487. doi:10.1093/gerona/glq028

Niculescu MD, Lupu DS (2011) Nutritional influence on epigenetics and effects on longevity. Curr Opin Clin Nutr Metab Care 14:35-40. doi:10.1097/MCO.0b013e328340ff7c

Nussey DH, Wilson AJ, Brommer JE (2007) The evolutionary ecology of individual phenotypic plasticity in wild populations. J Evol Biol 20:831-844. doi:10.1111/j.1420-9101. 2007.01300.x

Okumiya K et al (1999) A U-shaped association between home systolic blood pressure and four-year mortality in community-dwelling older men. J Am Geriatr Soc 47: 1415-1421

Olshansky SJ, Perry D, Miller RA, Butler RN (2007) Pursuing the longevity dividend: scientific goals for an aging world.
Ann N Y Acad Sci 1114:11-13. doi:10.1196/annals.1396. 050

Palatini P (1999) Need for a revision of the normal limits of resting heart rate. Hypertension 33:622-625

Parsons PA (1996) The limit to human longevity: an approach through a stress theory of ageing. Mech Ageing Dev 87:211-218

Parsons PA (2002) Life span: does the limit to survival depend upon metabolic efficiency under stress? Biogerontology 3:233-241

Parsons PA (2007) The ecological stress theory of aging and hormesis: an energetic evolutionary model. Biogerontology 8:233-242. doi:10.1007/s10522-007-9080-z

Protogerou AD et al (2007) Diastolic blood pressure and mortality in the elderly with cardiovascular disease. Hypertension 50:172-180

Riggs JE (1992) Aging and mortality: manifestations of natural 'non-selection'. Mech Ageing Dev 62:127-135

Rose G et al (2001) Paradoxes in longevity: sequence analysis of mtDNA haplogroup $\mathrm{J}$ in centenarians. Eur J Hum Genet 9:701-707. doi:10.1038/sj.ejhg.5200703

Savory FR, Benton TG, Varma V, Hope IA, Sait SM (2014) Stressful environments can indirectly select for increased longevity. Ecol Evol 4:1176-1185. doi:10.1002/ece3. 1013

Scheiner SM, Holt RD (2012) The genetics of phenotypic plasticity. X. Variation versus uncertainty. Ecol Evol 2:751-767. doi:10.1002/ece3.217

Seeman TE, McEwen BS, Rowe JW, Singer BH (2001) Allostatic load as a marker of cumulative biological risk: MacArthur studies of successful aging. Proc Natl Acad Sci USA 98:4770-4775

Semenchenko GV, Khazaeli AA, Curtsinger JW, Yashin AI (2004) Stress resistance declines with age: analysis of data from a survival experiment with Drosophila melanogaster. Biogerontology 5:17-30

Shega JW, Dale W, Andrew M, Paice J, Rockwood K, Weiner DK (2012) Persistent pain and frailty: a case for homeostenosis. J Am Geriatr Soc 60:113-117. doi:10.1111/j. 1532-5415.2011.03769.x

Sisodia S, Singh BN (2012) Experimental evidence for nutrition regulated stress resistance in Drosophila ananassae. PLoS One 7:e46131. doi:10.1371/journal.pone.0046131

Solovieff N, Cotsapas C, Lee PH, Purcell SM, Smoller JW (2013) Pleiotropy in complex traits: challenges and strategies. Nat Rev Genet 14:483-495. doi:10.1038/ $\operatorname{nrg} 3461$

Strehler BL, Mildvan AS (1960) General theory of mortality and aging Science 132:14-21

Thinnes FP (2012) Why cancer survivors have a lower risk of Alzheimer disease. MGM 107:630-631. doi:10.1016/j. ymgme.2012.06.016

Tremolizzo L, Rodriguez-Menendez V, Brighina L, Ferrarese C (2006) Is the inverse association between Alzheimer's disease and cancer the result of a different propensity to methylate DNA? Med Hypotheses 66:1251-1252. doi:10. 1016/j.mehy.2005.12.022

Troiano RP, Frongillo EA, Sobal J, Levitsky DA (1996) The relationship between body weight and mortality: a 
quantitative analysis of combined information from existing studies. Int J Obesity 20:63-75

Troncale JA (1996) The aging process: physiologic changes and pharmacologic implications. Postgrad Med 99(111-114): $120-122$

Ukraintseva SV et al (2010) Trade-offs between cancer and other diseases: do they exist and influence longevity? Rejuvenation Res 13:387-396. doi:10.1089/rej.2009.0941

Ukraintseva S, Arbeev K, Kulminski A, Akushevich I, Wu D, Yashin A (2012) Genetic trade-offs may explain some paradoxes of genetics of human longevity. Paper presented at the ASHG 2012 annual meeting, San Francisco, November 6-10, 2012

van Vliet-Ostaptchouk JV et al (2013) Pleiotropic effects of obesity-susceptibility loci on metabolic traits: a metaanalysis of up to 37,874 individuals. Diabetologia 56:2134-2146. doi:10.1007/s00125-013-2985-y

Vaupel JW, Yashin AI (1985) Heterogeneity's ruses: some surprising effects of selection on population dynamics. Am Stat 39:176-185

Vaupel JW, Yashin AI (1987) Repeated resuscitation: how lifesaving alters life tables. Demography 24:123-135

Vaupel JW, Manton KG, Stallard E (1979) The impact of heterogeneity in individual frailty on the dynamics of mortality. Demography 16:439-454

Vaupel JW et al (1998) Biodemographic trajectories of longevity. Science $280: 855-860$

Vermeulen CJ, Loeschcke V (2007) Longevity and the stress response in Drosophila. Exp Gerontol 42:153-159. doi:10. 1016/j.exger.2006.09.014

Walter S et al (2011) A genome-wide association study of aging. Neurobiol Aging. doi:10.1016/j.neurobiolaging.2011.05.026

Warner $\mathrm{H}$ et al (2005) Science fact and the SENS agenda. What can we reasonably expect from ageing research? EMBO Rep 6:1006-1008. doi:10.1038/sj.embor.7400555

Westin S, Heath I (2005) Thresholds for normal blood pressure and serum cholesterol. Br Med J 330:1461-1462

Wienke A (2010) Frailty models in survival analysis. Chapman \& Hall/CRC, Boca Raton

Witteman JCM, Grobbee DE, Valkenburg HA, Vanhemert AM, Stijnen T, Burger H, Hofman A (1994) J-shaped relation between change in diastolic blood pressure and progression of aortic atherosclerosis. Lancet 343:504-507

Woodbury MA, Manton KG (1977) A random-walk model of human mortality and aging. Theor Popul Biol 11:37-48

Wu D, Cypser JR, Yashin AI, Johnson TE (2008) The U-shaped response of initial mortality in Caenorhabditis elegans to mild heat shock: does it explain recent trends in human mortality? J GerontologySer A 63:660-668

Yashin AI, Iachine IA (1995) Survival of related individuals: an extension of some fundamental results of heterogeneity analysis. Math Popul Stud 5:321-377

Yashin AI, Iachine IA (1999a) Dependent hazards in multivariate survival problems. J Multivar Anal 71:241-261. doi:10.1006/jmva.1999.1848

Yashin AI, Iachine IA (1999b) What difference does the dependence between durations make? Insights for population studies of aging. Lifetime Data Anal 5:5-22

Yashin AI, Jazwinski SM (2014) Aging and health: a systems biology perspective. Cytogenet Genome Res 144:77-154
Yashin AI, Manton KG, Stallard E (1986) Evaluating the effects of observed and unobserved diffusion processes in survival analysis of longitudinal data. Math Model 7:1353-1363. doi:10.1016/0270-0255(86)90085-0

Yashin AI, Vaupel JW, Iachine IA (1994) A duality in aging: the equivalence of mortality models based on radically different concepts. Mech Ageing Dev 74:1-14

Yashin AI, Vaupel JW, Iachine IA (1995) Correlated individual frailty: an advantageous approach to survival analysis of bivariate data. Math Popul Stud 5(145-159):183. doi:10. 1080/08898489509525394

Yashin AI et al (1999) Genes, demography, and life span: the contribution of demographic data in genetic studies on aging and longevity. Am J Hum Genet 65:1178-1193. doi: $10.1086 / 302572$

Yashin AI et al (2000) Genes and longevity: lessons from studies of centenarians. J Gerontol A Biol Sci Med Sci 55:B319-B328

Yashin AI, Begun AS, Boiko SI, Ukraintseva SV, Oeppen J (2001a) The new trends in survival improvement require a revision of traditional gerontological concepts. Exp Gerontol 37:157-167

Yashin AI et al (2001b) Have the oldest old adults ever been frail in the past? A hypothesis that explains modern trends in survival. J Gerontol A Biol Sci Med Sci 56:B432-B442

Yashin AI, Begun AS, Boiko SI, Ukraintseva SV, Oeppen J (2002a) New age patterns of survival improvement in Sweden: do they characterize changes in individual aging? Mech Ageing Dev 123:637-647

Yashin AI, Ukraintseva SV, Boiko SI, Arbeev KG (2002b) Individual aging and mortality rate: how are they related? Soc Biol 49:206-217

Yashin AI, Arbeev KG, Ukraintseva SV (2007) The accuracy of statistical estimates in genetic studies of aging can be significantly improved. Biogerontology 8:243-255. doi:10. 1007/s10522-006-9072-4

Yashin AI, Ukraintseva SV, Akushevich IV, Arbeev KG, Kulminski A, Akushevich L (2009) Trade-off between cancer and aging: what role do other diseases play? Evidence from experimental and human population studies. Mech Ageing Dev 130:98-104. doi:10.1016/j.mad.2008.03.006

Yashin AI, Akushevich I, Arbeev KG, Kulminski A, Ukraintseva S (2011) Joint analysis of health histories, physiological states, and survival. Math Popul Stud 18:207-233

Yashin AI, Arbeev KG, Akushevich I, Kulminski A, Ukraintseva SV, Stallard E, Land KC (2012a) The quadratic hazard model for analyzing longitudinal data on aging, health, and the life span. Phys Life Rev 9:177-188. doi:10.1016/j. plrev.2012.05.002

Yashin AI, Wu D, Arbeev KG, Stallard E, Land KC, Ukraintseva SV (2012b) How genes influence life span: the biodemography of human survival. Rejuvenation Res 15:374-380. doi:10.1089/rej.2011.1290

Yashin AI et al (2013a) How lifespan associated genes modulate aging changes: lessons from analysis of longitudinal data. Front Genet 4:3. doi:10.3389/fgene.2013.00003

Yashin AI et al (2013b) How the quality of GWAS of human lifespan and health span can be improved. Front Genet. doi:10.3389/fgene. 2013.00125 
Yashin AI et al (2014) Genetic structures of population cohorts change with increasing age: Implications for genetic analyses of human aging and life span. Ann Gerontol Geriatr Res 1:1020

Zajacova A, Goldman N, Rodriguez G (2009) Unobserved heterogeneity can confound the effect of education on mortality. Math Popul Stud 16:153-173. doi:10.1080/ 08898480902790528

Zheng H, Yang Y, Land KC (2011) Heterogeneity in the StrehlerMildvan general theory of mortality and aging. Demography 48:267-290. doi:10.1007/s13524-011-0013-8 